\title{
The Strength Model of Self-Control
}

\author{
Roy F. Baumeister, ${ }^{1}$ Kathleen D. Vohs, ${ }^{2}$ and Dianne M. Tice ${ }^{1}$ \\ ${ }^{1}$ Florida State University and ${ }^{2}$ University of Minnesota
}

\begin{abstract}
Self-control is a central function of the self and an important key to success in life. The exertion of self-control appears to depend on a limited resource. Just as a muscle gets tired from exertion, acts of self-control cause short-term impairments (ego depletion) in subsequent self-control, even on unrelated tasks. Research has supported the strength model in the domains of eating, drinking, spending, sexuality, intelligent thought, making choices, and interpersonal behavior. Motivational or framing factors can temporarily block the deleterious effects of being in a state of ego depletion. Blood glucose is an important component of the energy.
\end{abstract}

KEYWORDS—self-control; ego depletion; willpower; impulse; strength

Every day, people resist impulses to go back to sleep, to eat fattening or forbidden foods, to say or do hurtful things to their relationship partners, to play instead of work, to engage in inappropriate sexual or violent acts, and to do countless other sorts of problematic behaviors-that is, ones that might feel good immediately or be easy but that carry long-term costs or violate the rules and guidelines of proper behavior. What enables the human animal to follow rules and norms prescribed by society and to resist doing what it selfishly wants?

Self-control refers to the capacity for altering one's own responses, especially to bring them into line with standards such as ideals, values, morals, and social expectations, and to support the pursuit of long-term goals. Many writers use the terms selfcontrol and self-regulation interchangeably, but those who make a distinction typically consider self-control to be the deliberate, conscious, effortful subset of self-regulation. In contrast, homeostatic processes such as maintaining a constant body temperature may be called self-regulation but not self-control.

Address correspondence to Roy F. Baumeister, Florida State University, Department of Psychology, 1107 W. Call Street, Tallahassee, FL 32306-4301; e-mail: baumeister@psy.fsu.edu.
Self-control enables a person to restrain or override one response, thereby making a different response possible.

Self-control has attracted increasing attention from psychologists for two main reasons. At the theoretical level, self-control holds important keys to understanding the nature and functions of the self. Meanwhile, the practical applications of self-control have attracted study in many contexts. Inadequate self-control has been linked to behavioral and impulse-control problems, including overeating, alcohol and drug abuse, crime and violence, overspending, sexually impulsive behavior, unwanted pregnancy, and smoking (e.g., Baumeister, Heatherton, \& Tice, 1994; Gottfredson \& Hirschi, 1990; Tangney, Baumeister, \& Boone, 2004; Vohs \& Faber, 2007). It may also be linked to emotional problems, school underachievement, lack of persistence, various failures at task performance, relationship problems and dissolution, and more.

\section{LIMITED RESOURCES}

Folk discussions of self-control have long invoked the idea of willpower, which implies a kind of strength or energy. During the heyday of the behaviorist and cognitive revolutions, however, psychology had little use for theorizing in energy terms, and self theories in particular had scarcely mentioned energy since Freud. However, in the 1990s, research findings began to point toward an energy model of self-control. There might be something to the willpower notion after all.

The idea that self-control depended on a limited energy resource was suggested by us (Baumeister et al., 1994) based on our review of multiple research literatures. We observed that self-control appeared vulnerable to deterioration over time from repeated exertions, resembling a muscle that gets tired. The implication was that effortful self-regulation depends on a limited resource that becomes depleted by any acts of self-control, causing subsequent performance even on other self-control tasks to become worse.

The basic approach to testing the depleted-resource hypothesis was to have some research participants perform a first self-control task, while others performed a comparable but neutral task, and 
then all would move on to perform a second, unrelated selfcontrol task. If self-control consumes a limited resource, then performing the first task should deplete the person's resource, leaving less available for the second task-and therefore causing poorer performance on the second task. Other theories would make different predictions. For example, if self-control mainly involved activating a cognitive schema or mental program, then the first self-control task should prime the schema and activate the self-control system, so performance on the second self-control task should improve, not worsen.

Early laboratory evidence for depleted resources in selfregulation was reported by Muraven, Tice, and Baumeister (1998) and Baumeister, Bratslavsky, Muraven, and Tice (1998). In one study, watching an emotionally evocative film while trying either to amplify or to stifle one's emotional response caused poorer performance on a subsequent test of physical (handgrip) stamina, as compared to watching the film without trying to control one's emotions. (Stamina counts as a measure of self-control because it involves resisting fatigue and overriding the urge to quit.) In another study, suppressing a forbidden thought weakened people's ability to stifle laughter afterward. In another, resisting the temptation to eat chocolates and cookies (and making oneself eat health-promoting but unappetizing radishes instead) caused participants to give up faster on a subsequent frustrating task, as compared to people who had not exerted self-control (see Fig. 1). These studies all pointed toward the conclusion that the first self-control task consumed and depleted some kind of psychological resource that was therefore less available to help performance on the second self-control task.

The term ego depletion was coined to refer to the state of diminished resources following exertion of self-control (or other tasks that might deplete the same resource). These ego-depletion effects are not due to a diminished a sense of self-efficacy or to the inference that one is poor at self-control. Wallace and Baumeister (2002) explicitly manipulated feedback about success and failure at self-control and measured self-efficacy, but neither factor had any discernible impact on the ego-depletion patterns. Nor

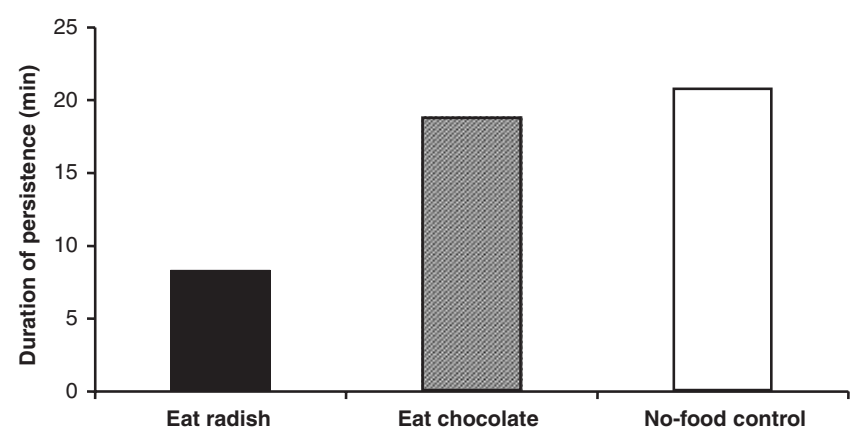

Fig. 1. Speed of giving up on an unsolvable task after eating chocolate or exerting self-control to resist chocolate in favor of radishes on a previous task (as compared to a no-food control). From Baumeister, Bratslavsky, Muraven, \& Tice, 1998. are these patterns due to participants refusing to exert themselves on the second task because they think they have done enough on the first task, as various findings have shown (see Baumeister, Gailliot, DeWall, \& Oaten, 2006); for example, it has been found that depleted participants will subject themselves to more boredom than will nondepleted ones on a second task.

Is willpower more than a metaphor? Gailliot et al. (2007) explored the role of glucose, a chemical in the bloodstream that can be converted to neurotransmitters and thus furnishes fuel for brain activity. Acts of self-control cause reductions in bloodglucose levels, which in turn predict poor self-control on behavioral tasks. Drinking a glass of lemonade with sugar helped counteract these effects, presumably by restoring glucose in the blood. Lemonade mixed with diet sweeteners (no glucose) had no such empowering effect.

\section{ELABORATING THE STRENGTH MODEL}

The analogy between self-control and a muscle was suggested by the early findings that self-control performance deteriorates after initial exertions, just as a muscle gets tired from exertion. Other revealing aspects of self-control performance also extend the resemblance to a muscle (see Box 1).

First, just as exercise can make muscles stronger, there are signs that regular exertions of self-control can improve willpower strength (for a review, see Baumeister et al., 2006). These improvements typically take the form of resistance to depletion, in the sense that performance at self-control tasks deteriorates at a slower rate. Targeted efforts to control behavior in one area, such as spending money or exercise, lead to improvements in unrelated areas, such as studying or household chores. And daily exercises in self-control, such as improving posture, altering verbal behavior, and using one's nondominant hand for simple tasks, gradually produce improvements in self-control as measured by laboratory tasks. The finding that these improvements carry over into tasks vastly different from the daily exercises shows that the improvements are not due to simply increasing skill or acquiring self-efficacy from practice.

Second, just as athletes begin to conserve their remaining strength when their muscles begin to tire, so do self-controllers when some of their self-regulatory resources have been expended. The severity of behavioral impairment during depletion depends in part on whether the person expects further challenges and demands. When people expect to have to exert self-control later, they will curtail current performance more severely than if no such demands are anticipated (Muraven, Shmueli, \& Burkley, 2006).

Third, and consistent with the conservation hypothesis, people can exert self-control despite ego depletion if the stakes are high enough. Offering cash incentives or other motives for good performance counteracts the effects of ego depletion (Muraven \& Slessareva, 2003). This may seem surprising but in 


\section{BOX 1.}

Contexts, Moderators, Mediators, and Implications of the Limited-Resource Effect

Responses that require self-regulation include

- Controlling thoughts

- Managing emotions

- Overcoming unwanted impulses (e.g., not eating tempting candies because of being on a diet)

- Fixing attention

- Guiding behavior

- Making many choices

Behaviors that are sensitive to depletion of self-regulatory resources include

- Eating among dieters

- Overspending

- Aggression after being provoked

- Sexual impulses

- Intelligent and logical decision making

Interpersonal processes that require self-regulatory resources include

- Self-presentation or impression management

- Kindness in response to a partner's bad behavior

- Dealing with demanding, difficult partners

- Interracial interactions

Moderators of ego depletion include

- Heightened motivation to achieve a goal

- Collectivistic cultural background

Physical indicators of ego depletion include

- Heart-rate variability

- Neural changes using electroencephalograph methods

Mediators of ego depletion include

- Subjective time perception (time perception is elongated-i.e., time moves slowly)

- Blood-glucose levels

Harmful effects of depletion may be counteracted through

- Humor and laughter

- Other positive emotions

- Cash incentives

- Implementation intentions ("if ... then" plans)

- Social goals (e.g., wanting to help people; wanting to be a good relationship partner)

fact it may be highly adaptive. Given the value and importance of the capacity for self-control, it would be dangerous for a person to lose that capacity completely, and so ego depletion effects may occur because people start conserving their remaining strength. When people do exert themselves on the second task, they deplete the resource even more, as reflected in severe impairments on a third task that they have not anticipated (Muraven et al., 2006).

To be sure, we think there are levels of depletion beyond which people may be unable to control themselves effectively, regardless of what is at stake. Pragmatic and ethical limitations have prevented us from showing this in laboratory work thus far. Again, the muscle analogy is relevant: Mildly tired athletes can indeed manage to summon the strength for a major exertion at decisive moments, but after a certain point fatigue becomes insurmountable.
How far the muscle analogy can be pushed remains an open question. Are there self-control states resembling sprained or injured muscles? One might speculate that burnout or other pathological states resemble the incapacities stemming from muscles that have been abused beyond their normal capacity for recovery.

Multiple lines of work have identified procedures that can moderate or counteract the effects of ego depletion. Inducing a state of positive emotion such as humor seems to have that effect (Tice, Baumeister, Shmueli, \& Muraven, 2007). Having implementation intentions-formulating "if-then" statements about how to behave in a situation prior to entering it—seems to be effective most likely because such intentions operate as behavioral plans and guidelines that reduce the need for executive control (Webb \& Sheeran, 2003). To be sure, none of these procedures clearly counteracts the depleted state in the sense of replenishing the depleted resource. Rather, they may all operate by inducing the person to expend more of the depleted resource. In contrast, there is some reason to think that replenishing glucose in the bloodstream does actually rectify the depletion by restoring the depleted resource (Gailliot et al., 2007).

\section{PRACTICAL APPLICATIONS}

Understanding self-control has potential applications across a broad spectrum of human behavior. At the positive end, selfcontrol is associated with good adjustment, secure attachment, and other favorable psychological states (Tangney et al., 2004). At the negative end, poor self-control is associated with elevated rates of psychopathological complaints and symptoms, as well as increased vulnerability to various substance-abuse and eating disorders (Tangney et al., 2004). Evidence that ego depletion contributes to a variety of problem behaviors-including excessive alcohol consumption, overeating, sexual misbehavior, prejudicial discrimination, and violence-is accumulating.

Intelligent behavior is vital to human success, and it depends partly on self-control. Some processes, such as rote memory, are fairly automatic and independent of executive control, and these appear to be relatively unaffected by depletion. But logical reasoning, extrapolation, and other controlled processes depend on control by the self, and performance on these tasks dips sharply when people are depleted (Schmeichel, Vohs, \& Baumeister, 2003).

Interpersonal processes also seem to hinge on self-regulatory operations, with some needing self-control more than others. Richeson and Shelton (2003) reasoned that self-control is needed for discussing delicate, sensitive issues-for instance talking about racial politics with a member of a different race-because one has to avoid saying anything that might give offense or be misinterpreted. The researchers had White participants engage in such a conversation with a Black person; afterwards, the participants showed impaired performance on the Stroop task, a classic measure of self-control in which participants are 
instructed to say the color in which other color words are printed (e.g., when seeing the word green printed in blue, the participant must override the automatic response of saying "green" in order to say "blue"). Having such a conversation with a member of one's own race does not deplete the self and impair subsequent self-control.

Presenting a desired image to others can also tax self-control strength resources (Vohs, Baumeister, \& Ciarocco, 2005). After exerting effort at managing the impression they made (e.g., when trying to convey a particular image while making a recording), people showed deficits at self-control. Moreover, and conversely, after people had exerted self-control, they were less effective at managing their behavior so as to make a good impression and in fact sometimes behaved in annoying or off-putting ways.

\section{IMPLICATIONS FOR THEORY}

The existence of a single energy resource that is used for a broad range of self-control acts suggests that self theory must move beyond merely cognitive models. The self is more than a network of cognitive schemas: It is a dynamic system able to manage behavior in advanced, complex, and biologically expensive ways.

The use of the body's energy for complex action control extends beyond self-control. Recent studies indicate that the same energy is used for effortful decision making, as well as for active rather than passive responses (e.g., Vohs et al., 2007). These seem to correspond to what laypersons understand as "free will," namely the ability to override impulses, behave morally, show initiative, and behave according to rational choices (Baumeister, in press).

Most broadly, the strength model of self-control offers suggestions about how and why the human self evolved in its current form. The functional purposes of the self almost certainly include managing behavior toward fostering enlightened self-interest and facilitating group membership by garnering social acceptance. Self-control is helpful for both these goals. The role of energy suggests that self-control is a complex, biologically expensive form of behavior. Thus, we may infer that, to enable humans to create and sustain the complicated groups to which they belong, including cultural systems, evolution had to find a way to use the body's energy to control behavior in these advanced and subtle ways. For example, human beings everywhere regulate their behavior according to various rules, such as social norms, moral principles, and laws.

\section{FURTHER DIRECTIONS}

A particularly broad and important question is what other forms of behavior (beyond self-control and choice) use this limited resource: How special is this form of mental effort? We noted that success at building self-control through exercises has been inconsistent, so it is also necessary to explore why some regimens work better than others. Finding a reliable way to improve self-control would not only shed light on how the self functions but would also have practical value for therapists, coaches, educators, parents, and many others.

Identifying the biological substrates of self-control depletion (and replenishment) would be another helpful direction for further work. Better understanding of the developmental process would likewise strengthen the theory and make it more applicable to human welfare and problems.

\section{CONCLUDING REMARKS}

Psychology can contribute to society by finding ways to enable people to live healthier, more successful, and more satisfying lives. Self-control is a promising avenue to achieve this. It appears to facilitate success in life in many spheres, and, crucially, it appears amenable to improvement. Indeed, self-control can be grouped with intelligence among the (rather few) traits that are known to contribute to success in human life across a broad variety of spheres; yet unlike intelligence, self-control appears amenable to improvement from psychological interventions, even in adulthood. The strength model can illuminate how self-control operates and functions. By building on this knowledge, psychology may be able to improve the mental health and well-being of many people.

\section{Recommended Reading}

Baumeister, R.F., Schmeichel, B.J., \& Vohs, K.D. (2007). Self-regulation and the executive function: The self as controlling agent. In A. Kruglanski \& E.T. Higgins (Eds.), Social psychology: Handbook of basic principles (2nd ed., pp. 516-539). New York: Guilford. A recent and thorough overview of the research in a broad context.

Gailliot, M.T., Baumeister, R.F., DeWall, C.N., Maner, J.K., Plant, E.A., \& Tice, D.M. et al. (2007). (See References). Reports experiments linking behavioral self-control measures to blood glucose.

Baumeister, R.F., Gailliot, M., DeWall, C.N., \& Oaten, M. (2006). (See References). An overview of the research program on self-control with emphasis on personality implications and alternative explanations.

Acknowledgments - The authors gratefully acknowledge research support from the Templeton Foundation.

\section{REFERENCES}

Baumeister, R.F. (in press). Free will in scientific psychology. Perspectives on Psychological Science.

Baumeister, R.F., Bratslavsky, E., Muraven, M., \& Tice, D.M. (1998). Ego depletion: Is the active self a limited resource? Journal of Personality and Social Psychology, 74, 1252-1265.

Baumeister, R.F., Gailliot, M., DeWall, C.N., \& Oaten, M. (2006). Selfregulation and personality: How interventions increase regulatory success, and how depletion moderates the effects of traits on behavior. Journal of Personality, 74, 1773-1801. 
Baumeister, R.F., Heatherton, T.F., \& Tice, D.M. (1994). Losing control: How and why people fail at self-regulation. San Diego, CA: Academic Press.

Gailliot, M.T., Baumeister, R.F., DeWall, C.N., Maner, J.K., Plant, E.A., \& Tice, D.M., et al. (2007). Self-control relies on glucose as a limited energy source: Willpower is more than a metaphor. Journal of Personality and Social Psychology, 92, 325-336.

Gottfredson, M.R., \& Hirschi, T. (1990). A general theory of crime. Stanford, CA: Stanford University Press.

Muraven, M., Shmueli, D., \& Burkley, E. (2006). Conserving self-control strength. Journal of Personality and Social Psychology, 91, 524-537.

Muraven, M., \& Slessareva, E. (2003). Mechanisms of self-control failure: Motivation and limited resources. Personality and Social Psychology Bulletin, 29, 894-906.

Muraven, M., Tice, D.M., \& Baumeister, R.F. (1998). Self-control as limited resource: Regulatory depletion patterns. Journal of Personality and Social Psychology, 74, 774-789.

Richeson, J.A., \& Shelton, J.N. (2003). When prejudice does not pay: Effects of interracial contact on executive function. Psychological Science, 14, 287-290.

Schmeichel, B.J., Vohs, K.D., \& Baumeister, R.F. (2003). Intellectual performance and ego depletion: Role of the self in logical reasoning and other information processing. Journal of Personality and Social Psychology, 85, 33-46.
Tangney, J.P., Baumeister, R.F., \& Boone, A.L. (2004). High self-control predicts good adjustment, less pathology, better grades, and interpersonal success. Journal of Personality, 72, 271-322.

Tice, D.M., Baumeister, R.F., Shmueli, D., \& Muraven, M. (2007). Restoring the self: Positive affect helps improve self-regulation following ego depletion. Journal of Experimental Social Psychology, 43, 379-384.

Vohs, K.D., Baumeister, R.F., \& Ciarocco, N. (2005). Self-regulation and self-presentation: Regulatory resource depletion impairs impression management and effortful self-presentation depletes regulatory resources. Journal of Personality and Social Psychology, 88, 632-657.

Vohs, K.D., Baumeister, R.F., Twenge, J.M., Nelson, N.M., Rawn, C.D., Schmeichel, B.J., \& Tice, D.M. (2007) Making choices impairs subsequent self-control: A limited resource account of decision making, selfregulation, and active initiative. Manuscript submitted for publication.

Vohs, K.D., \& Faber, R.J. (2007). Spent resources: Self-regulatory resource availability affects impulse buying. Journal of Consumer Research, 33, 537-547.

Wallace, H.M., \& Baumeister, R.F. (2002). The effects of success versus failure feedback on further self-control. Self and Identity, 1 , $35-41$.

Webb, T.L., \& Sheeran, P. (2003). Can implementation intentions help to overcome ego-depletion? Journal of Experimental Social Psychology, 39, 279-286. 